\title{
im DETARL
}

\section{Einfamilienhäuser}

2. erweiterte Auflage

Christian Schittich (Hrsg.)

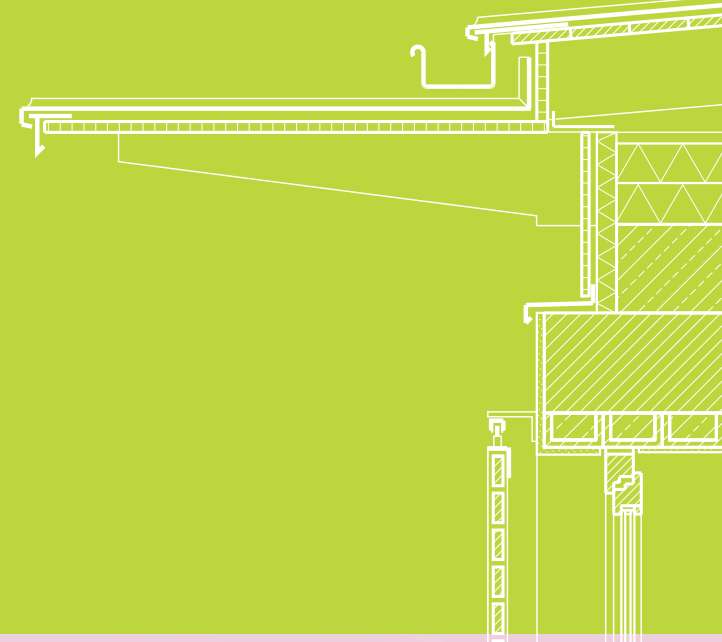

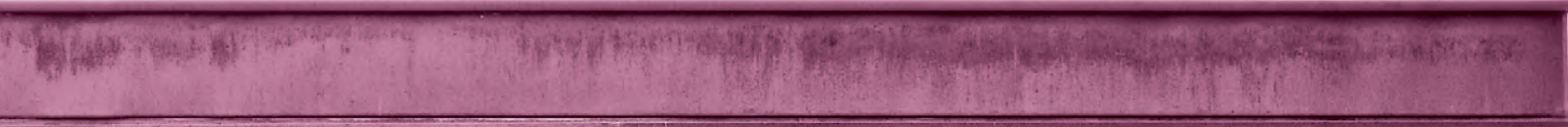

Hân
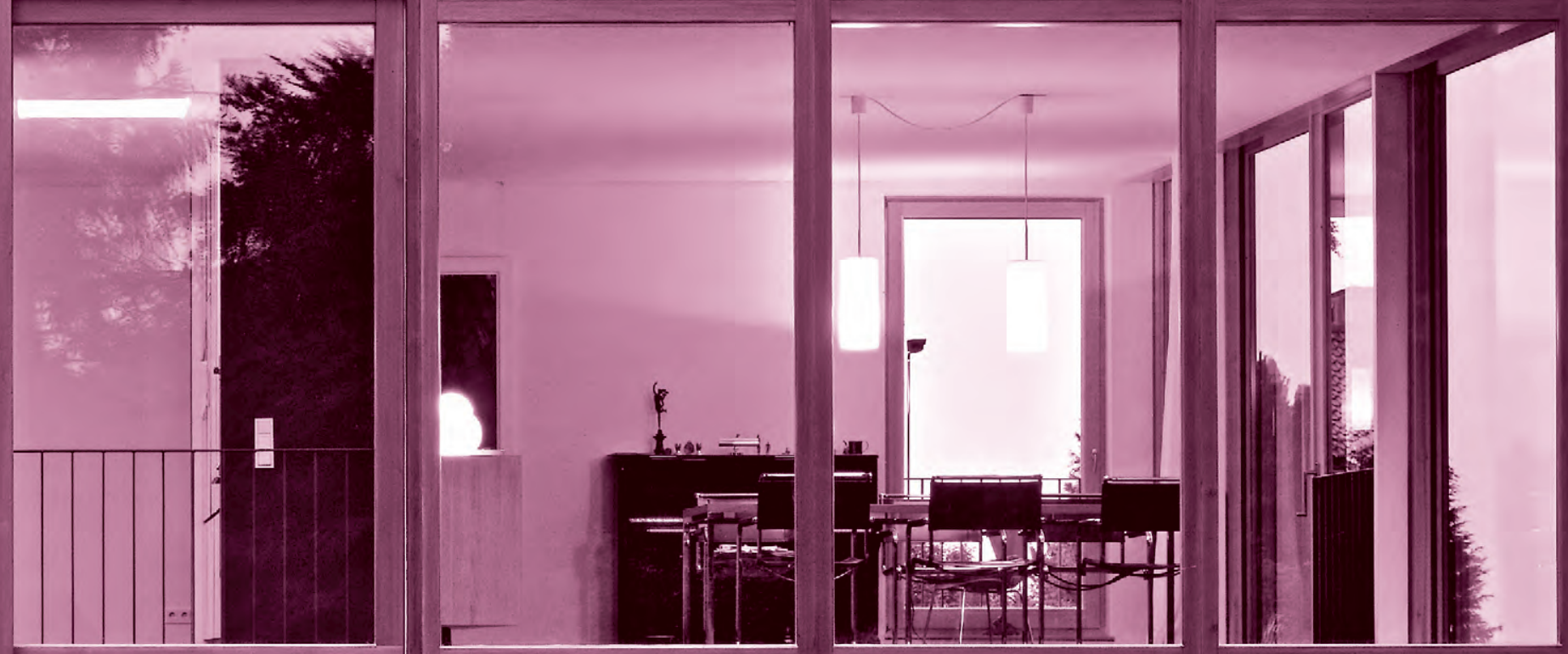

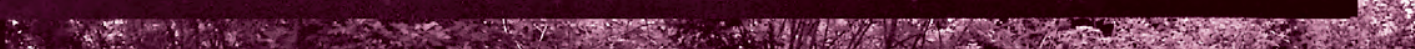

$x^{2}=x^{2}$
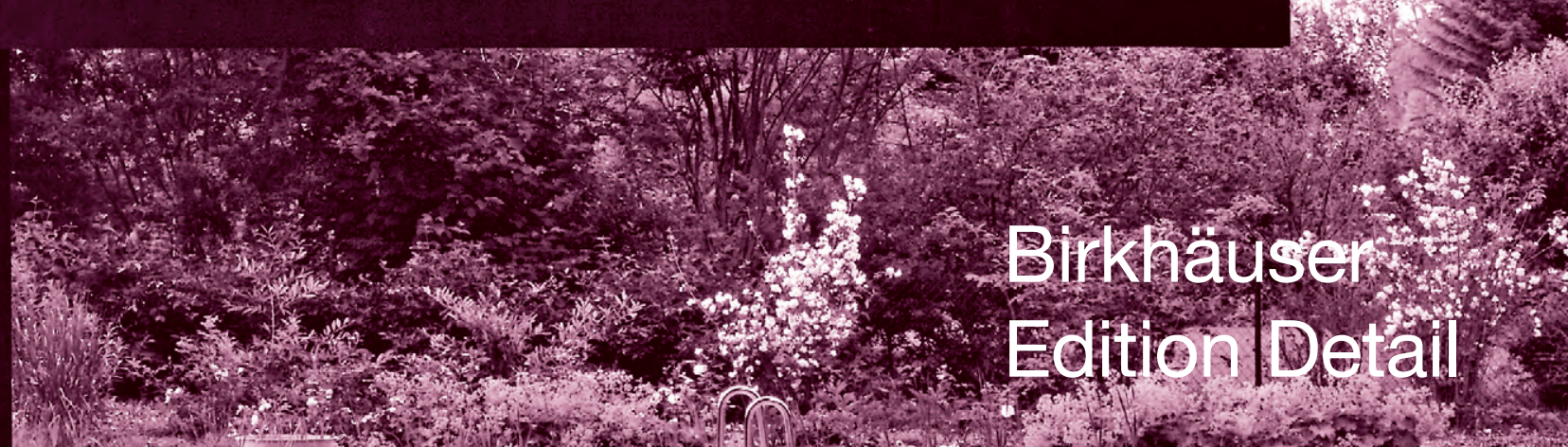

im DETAIL Einfamilienhäuser 



\title{
im DETAI L Einfamilienhäuser 2. erweiterte Auflage
}

\author{
Christian Schittich (Hrsg.)
}

mit Textbeiträgen von

Rüdiger Krisch

Gert Kähler 
Herausgeber: Christian Schittich

Projektleitung: Ingrid Geisel, Andrea Wiegelmann

Redaktionelle Mitarbeit: Kathrin Draeger, Alexander Felix, Astrid Donnert, Cordula Rau

Zeichnungen: Kathrin Draeger, Marion Griese, Emese Köszegi, Andrea Saiko, Martin Hemmel, Norbert Graeser

DTP: Peter Gensmantel, Andrea Linke, Roswitha Siegler, Simone Soesters

Dieses Buch ist eine Kooperation von

DETAIL - Zeitschrift für Architektur + Baudetail und

Birkhäuser - Verlag für Architektur

Die Deutsche Bibliothek - CIP-Einheitsaufnahme

Im Detail: Einfamilienhäuser: Konzepte, Planung, Konstruktion /

Christian Schittich (Hrsg.). - Basel; Boston; Berlin: Birkhäuser, 2005

Engl. Ausg. u. d. T.: In detail: single family houses

ISBN 10: 3-7643-7277-X

ISBN 13: 978-3-7643-7277-4

๑ 2005 Institut für internationale Architektur-Dokumentation GmbH \& Co. KG, Postfach 3306 60, D-80066 München und Birkhäuser - Verlag für Architektur, Postfach 133, CH-4010 Basel, Schweiz

Dieses Werk ist urheberrechtlich geschützt. Die dadurch begründeten Rechte, insbesondere die der Übersetzung, des Nachdrucks, des Vortrags, der Entnahme von Abbildungen und Tabellen, der Funksendung, der Mikroverfilmung oder der Vervielfältigung auf anderen Wegen und der Speicherung in Datenverarbeitungsanlagen, bleiben, auch bei nur auszugsweiser Verwertung, vorbehalten. Eine Vervielfältigung dieses Werkes oder von Teilen dieses Werkes ist auch im Einzelfall nur in den Grenzen der gesetzlichen Bestimmungen des Urheberrechtsgesetzes in der jeweils geltenden Fassung zulässig. Sie ist grundsätzlich vergütungspflichtig. Zuwiderhandlungen unterliegen den Strafbestimmungen des Urheberrechts.

Gedruckt auf säurefreiem Papier, hergestellt aus chlorfrei gebleichtem Zellstoff (TCF $\infty)$.

Printed in Germany

Reproduktion: Karl Dörfel Reproduktions-GmbH, München

Druck und Bindung: Kösel GmbH \& Co. KG, Altusried-Krugzell 